\title{
Nursing Students' Perceptions of the Dedicated Education Unit Model in 2 UAE Hospitals
}

\author{
Rose Ann Hooper ${ }^{\mathrm{a}}$ Mohamad AlMekkawi $^{\mathrm{b}}$ Gerald Williams $^{\mathrm{c}}$ \\ Belinda Thompson ${ }^{\text {a }}$ Marlize Zeeman ${ }^{\text {a }}$ \\ ${ }^{a}$ Al Ain Hospital, Abu Dhabi Health Service (SEHA), Al Ain, United Arab Emirates; b Nursing Program, \\ Fatima College of Health Sciences, Al Ain, United Arab Emirates; 'Shaikh Shakhbout Medical City, \\ Abu Dhabi Health Service (SEHA), Abu Dhabi, United Arab Emirates
}

\section{Keywords}

Dedicated education unit · Nursing students · Student

clinical placement $\cdot$ Nursing preceptors

\section{Abstract}

Background: Initially developed in Australia, Dedicated Education Unit (DEU) is an innovative approach to support the growth and development of nursing students while on clinical placement in the hospital setting. With the increasing number of nursing students requiring clinical placement, nursing needed to explore further ways to support students and preceptors in the clinical area. Methods: The study followed a sequential explanatory mixed-methods design to investigate participants' perceptions of the effectiveness of the DEU model in improving nursing students' learning experiences. The DEU model was implemented in $2 \mathrm{Abu}$ Dhabi Health Services Company (SEHA) hospitals in AI Ain City, and feedback was obtained from both students and their preceptors via survey and focus group sessions. Results: The study showed positive results with students feeling supported to learn new knowledge and skills by their preceptors. Preceptors reported that they were better able to facilitate

\begin{tabular}{|c|c|}
\hline KARGER & $\begin{array}{l}\text { (C) } 2020 \text { The Author(s) } \\
\text { Published by S. Karger AG, Basel }\end{array}$ \\
\hline $\begin{array}{l}\text { karger@karger.com } \\
\text { www.karger.com/dmj }\end{array}$ & $\begin{array}{l}\text { This article is licensed under the Creative Commons Attribution- } \\
\text { NonCommercial-NoDerivatives } 4.0 \text { International License (CC BY- } \\
\text { NC-ND) (http://www.karger.com/Services/OpenAccessLicense). } \\
\text { Usage and distribution for commercial purposes as well as any dis- } \\
\text { tribution of modified material requires written permission. }\end{array}$ \\
\hline
\end{tabular}

student placements in an environment that supported learning. Conclusion: The introduction of the DEU model has supported increasing numbers of students in the clinical area and provided an improved environment for learning.

(c) 2020 The Author(s)

Published by S. Karger AG, Basel

\section{Introduction}

Clinical placements have a significant impact on nursing students' clinical learning and their preparation for the nursing profession [1]. Clinical placements aim to enhance students' critical thinking and communication skills, integrate taught theory and skills into practice, and apply learned ethical principles in real-life settings to function as a member of the healthcare team [2]. Healthcare and education sectors have a joint responsibility to ensure that nursing graduates enter the nursing workforce with enough knowledge, clinical skills, and confidence to practice in dynamic clinical environments that involve high levels of patients' acuity and nursing workloads.

SEHA, the corporate marketing name of "Abu Dhabi Health Services Company," is the largest healthcare orga- 
Table 1. The old model of clinical learning versus the DEU model

\begin{tabular}{lll}
\hline & Old model & DEU model \\
\hline Students per unit & $1-2$ & $>2$ \\
Students per preceptor & 1 & $>1$ \\
Preceptor knowledge of university curriculum & limited & detailed \\
College faculty member involvement onward & limited & intense \\
Number of units taking students & limited/focused \\
Engagement of senior nursing leadership in student education & limited & extensive \\
Students' learning responsibility & passive recipient & actively seeking learning opportunities
\end{tabular}

nization that owns and operates all public hospitals and clinics across the Emirate of Abu Dhabi in the UAE. SEHA hospitals are involved in training nursing students from several UAE universities, notably Fatima College of Health Sciences (FCHS). Both SEHA and FCHS are engaged in preparing clinical training experiences to help nursing students integrate and consolidate their theoretical knowledge, build up their professional identity, and improve their readiness to perform quality and safe nursing practice. However, arranging clinical training experiences for students at SEHA facilities has become challenging in recent years due to the increasing enrolment of nursing students at FCHS. This situation has necessitated creating a more innovative clinical training model in order to increase clinical training places at SEHA hospitals and improve the capacity of nursing preceptors to supervise more nursing students.

The preceptorship model of clinical training is a traditional model utilized in the majority of clinical facilities to prepare student nurses. Tuohy [3] stated that "there is a growing body of evidence that the preceptor model does not ensure quality learning opportunities for students and is equally unsatisfactory for Registered Nurses acting as preceptors." The Dedicated Education Unit (DEU) has been used in many countries with reported success [4]. The model was designed to help improve the clinical learning partnership between healthcare facilities and universities and to ensure the most efficacious and sustainable learning opportunity for students and staff in a resource-constrained environment. The DEU model provides a platform to bridge the gap between theory and practice and enhances the quality and safety competencies within the practice and education environments [5].

The decision to implement the DEU model at 2 SEHA hospitals aimed to provide an ideal clinical training environment for nursing students. In this new model, nursing students were expected to balance knowledge acquisition with the "being" and "doing" of professional nursing.
Nursing preceptors were also expected to provide direct and indirect students' supervision and collaborate with both faculty members and nurse educators to facilitate students' learning. Besides, faculty members were supposed to perform better guidance of the learning process, follow up on students' assessment, support learning with students and staff, and clarify students' scope of practice and supervision requirements. Therefore, the purpose of this study was to investigate participants' perceptions of the effectiveness of the DEU model in improving the learning experience of nursing students and their preceptors.

\section{The Dedicated Education Unit}

The DEU model of clinical training was initially developed at Flinders University School of Nursing and Midwifery in Australia in 1999 and then in the United States at Portland's School of Nursing in 2003 [6]. The DEU model has an advantage over the traditional clinical models to maintain consistency in the location of students' learning and in the nursing preceptors assigned to supervise nursing students during clinical training experiences. Staying on one specific unit for a significant period will allow students to build trust relations with the unit staff members, feel more welcomed, be more responsible for their learning, and develop better practical skills $[7,8]$.

Implementing the DEU model at 2 SEHA hospitals was an initial pilot program that aimed to expand upon the traditional model of clinical training, which was struggling to support the increased training demands of nursing students at the hospital settings. Application of the DEU model at SEHA hospitals involved a 3-month preliminary period in preparing the units and training the staff members, nursing preceptors, faculty members, and nurse managers to the requirements of the new model. Nursing students were then allocated to the selected inpatient units (adult, pediatric, medical, and surgical
Hooper/AlMekkawi/Williams/ Thompson/Zeeman 
wards) in line with their curriculum requirements. Each unit was developed into an optimal teaching environment through the collaborative efforts of staff nurses, nursing management, students, and faculty members. Moreover, each nursing student was assigned to a certified nursing preceptor who is oriented to the student's learning objectives and needs (Table 1). Students were allowed to provide all care required for their patient(s) under the supervision of nursing preceptors within the limits of their learning objectives. Besides, nursing preceptors were attentive and able to provide appropriate guidance to students. The preceptors tried to remain "hands-off," allowing students to practice "hands-on" care. FCHS faculty members were present on the hospital units throughout the shift providing further guidance to the students and preceptors as required. Moreover, all other nursing staff on the DEU were familiar with the learning model and the roles of the students, preceptors, nurse educators, and FCHS faculty.

\section{Methodology}

Design

The study followed a sequential explanatory mixed-methods design described by Creswel [9] in 2009 to investigate participants' perceptions of the effectiveness of the DEU model in improving nursing students' learning experiences. Data were collected sequentially over 2 phases. The first phase involved collecting quantitative data from a sample of nursing students and preceptors using the Student Clinical Learning Culture (SCLC) and the Support Instrument for Nurses Facilitating the Learning of Others (SINFLO) surveys. In the second phase, qualitative data were collected from a sample of nursing students. Collecting both quantitative and qualitative data provided the study with rich and complementary information that helped to gain an in-depth understanding of the study phenomenon and context.

\section{Sample}

In the first phase of the study, a convenience sample of nursing preceptors $(n=174)$ and nursing students $(n=142)$ was invited to complete an online version of the study surveys during regular clinical placements. Eighty-two nursing students and 105 preceptors completed the surveys, with a response rate of $57.7 \%$ for students and $60.3 \%$ for preceptors. In the second phase, 9 students were invited to participate in the focus group discussion in October 2018, and 7 students agreed to participate (77.78\%).

\section{Data Collection}

In the quantitative phase, 2 surveys were used to measure nursing students' and preceptors' perceptions of the effectiveness of the DEU model on students' learning experiences. The tools were administered after 4 consecutive semesters commencing in February 2016 and finishing in March 2018. The SCLC survey, developed by Henderson et al. $[10,11]$ in 2010, was sent via email to all students who were placed in the DEU units each semester. The SCLC is a valid and reliable tool that measures students' learning during clinical training experiences. It has 21 items to report students' perceptions using a Likert scale ( $1=$ strongly disagree, 2 = disagree, $3=$ neither agree nor disagree, $4=$ agree, and $5=$ strongly agree). No changes were made on the items for this study. The authors of the tool identified 4 subscales with good reliability: staff engagement 0.87 , student motivation 0.75 , student satisfaction 0.67 , and student dissatisfaction $0.78[10,12]$.

Secondly, the SINFLO survey, developed by Henderson et al. [13] in 2012, was sent via email to all nursing preceptors working with the students on the DEU units each semester. SINFLO is a valid and reliable tool used to measure the perception of nurses on the level of support they receive when engaged in students' learning. The survey is composed of 17 items to report nurses' perceptions using a Likert scale ( 1 = strongly disagree, 2 = disagree, $3=$ neither agree nor disagree, $4=$ agree, and $5=$ strongly agree). No changes were made on the items in this study. Factor analysis conducted by the authors identified 5 core subscales with good reliability: workload 0.953 , acknowledgment 0.858 , communication 0.847 , preparation 0.942 , and teamwork $0.852[12,13]$.

In the qualitative phase, a focus group discussion was conducted with 7 students in October 2018. The research team chose to invite students who had not commenced the graduate nurse intern program in the hospitals to avoid any influence associated with being permanently based in the hospital setting. An interview guide was prepared following an extensive review of the literature and review of the survey findings. All students received email invitations to attend the discussion session. They were provided with a copy of the ethics committee approval and consent forms detailing the purpose, process, rights, and responsibilities of all participants. The discussion was facilitated and recorded by 2 members of the research team. Data saturation was reached when no new information/concepts were coming from the students. The responses were analyzed for themes by the panel and other investigators following completion of the interviews.

\section{Data Analysis}

Quantitative data were entered into an Excel $^{\circledR}$ (Microsoft) spreadsheet by one member of the research team. Descriptive statistics were used to determine participants' perceptions of the effectiveness of the DEU model on students' learning experiences. Qualitative data were analyzed using content analysis [14]. All data acquired through focus group discussions were transcribed verbatim. All transcripts were then read thoroughly and repeatedly to identify similar themes. Three themes emerged from content analysis: students' understanding of the DEU model, students' learning environment, and students' expectations. To maintain the trustworthiness of the data, the interview transcriptions and themes were checked by one of the participants, in addition to sharing the content with one qualitative research expert.

\section{Results}

Eighty-four students participated in this study. All were full-time female students studying Bachelor of Science in Nursing (BSN) at FCHS, female Arab students, and their ages ranged from 19 to 27 years. Also, 105 nurs- 
Table 2. Student Clinical Learning Culture surveys scores

\begin{tabular}{|c|c|c|c|c|c|c|c|c|c|c|}
\hline & & \multicolumn{2}{|c|}{$\begin{array}{l}\text { April 2016, } \\
\text { Group 1 }\end{array}$} & \multicolumn{2}{|c|}{$\begin{array}{l}\text { December 2016, } \\
\text { Group } 2\end{array}$} & \multicolumn{2}{|c|}{$\begin{array}{l}\text { April 2017, } \\
\text { Group } 3\end{array}$} & \multicolumn{2}{|c|}{$\begin{array}{l}\text { December 2017, } \\
\text { Group } 4\end{array}$} & Total \\
\hline & \multirow{5}{*}{$\begin{array}{l}\text { Surveys sent, } n \\
\text { Survey responses, } n\end{array}$} & & & & & & & & & \\
\hline \multirow{4}{*}{$\begin{array}{l}1 \\
2\end{array}$} & & \multirow{2}{*}{\multicolumn{2}{|c|}{$\begin{array}{l}23 \\
10\end{array}$}} & \multicolumn{2}{|l|}{26} & \multicolumn{2}{|l|}{46} & \multicolumn{2}{|l|}{47} & \multirow{2}{*}{$\begin{array}{l}142 \\
82\end{array}$} \\
\hline & & & & 16 & & 28 & & 28 & & \\
\hline & & \multicolumn{2}{|c|}{$\begin{array}{l}\text { April 2016, } \\
\text { Group 1 }\end{array}$} & \multicolumn{2}{|c|}{$\begin{array}{l}\text { December 2016, } \\
\text { Group } 2\end{array}$} & \multicolumn{2}{|c|}{$\begin{array}{l}\text { April 2017, } \\
\text { Group } 3\end{array}$} & \multicolumn{2}{|c|}{$\begin{array}{l}\text { December 2017, } \\
\text { Group } 4\end{array}$} & \multirow{2}{*}{$\begin{array}{l}\text { Total } \\
\begin{array}{l}\text { weighted } \\
\text { average }\end{array}\end{array}$} \\
\hline & & mean & median & mean & median & mean & median & mean & median & \\
\hline & Questions & & & & & & & & & \\
\hline 1 & I put effort into what I do in the ward & 4.5 & 5 & 4.4 & 4.5 & 4.1 & 4 & 4.5 & 5 & 4.4 \\
\hline 2 & Nurses in this ward tell me how and why they are doing things & 4.4 & 4 & 4.3 & 4 & 4.0 & 4 & 4.0 & 5 & 4.1 \\
\hline 3 & Staff are punctual & 4.0 & 4 & 4.0 & 4 & 3.9 & 4 & 4.1 & 4 & 4.0 \\
\hline 4 & This is a disorganized clinical placement & 2.8 & 3 & 2.4 & 2 & 2.0 & 2 & 3.1 & 4 & 2.6 \\
\hline 5 & The nurse working with me goes out of his/her way to help me & 3.6 & 4 & 3.8 & 4 & 3.8 & 4 & 3.9 & 4 & 3.8 \\
\hline 6 & $\begin{array}{l}\text { The nurse working with me helps me when I am having } \\
\text { trouble with the work }\end{array}$ & 4.5 & 5 & 4.3 & 4.5 & 4.0 & 4 & 4.1 & 5 & 4.2 \\
\hline 7 & This clinical placement is a waste of time & 2.1 & 2 & 1.7 & 2 & 1.9 & 2 & 4.1 & 5 & 2.7 \\
\hline 8 & The facilitator talks with me as an individual & 3.9 & 4 & 4.0 & 4 & 4.0 & 4 & 4.0 & 4 & 4.0 \\
\hline 9 & The nurse often thinks of interesting learning activities & 3.7 & 4 & 3.6 & 4 & 3.7 & 4 & 3.7 & 4 & 3.7 \\
\hline 10 & The nurse working with me considers my feelings & 4.0 & 4 & 3.9 & 4 & 4.0 & 4 & 3.8 & 4 & 3.9 \\
\hline 11 & Ward assignments are clear so that I know what to do & 3.9 & 4 & 3.9 & 4 & 3.9 & 4 & 4.3 & 4 & 4.0 \\
\hline 12 & I pay attention to what others are saying & 4.6 & 5 & 4.8 & 5 & 4.3 & 4 & 4.4 & 5 & 4.5 \\
\hline 13 & This clinical placement is boring & 1.9 & 1 & 2.1 & 1.5 & 1.8 & 2 & 4.1 & 4 & 2.6 \\
\hline 14 & I have a say in how the shift is spent & 3.4 & 3 & 3.5 & 3 & 3.6 & 4 & 3.8 & 4 & 3.6 \\
\hline 15 & There are opportunities for me to proceed at my own pace & 3.8 & 4 & 3.8 & 4 & 3.8 & 4 & 3.9 & 4 & 3.9 \\
\hline 16 & I enjoy coming to this ward & 4.0 & 4 & 3.7 & 4 & 3.8 & 4 & 3.9 & 4 & 3.8 \\
\hline 17 & The nurses are unfriendly and inconsiderate towards students & 2.4 & 2 & 2.6 & 3 & 2.0 & 1.5 & 3.1 & 3 & 2.6 \\
\hline 18 & Workload allocation in this ward is carefully planned & 4.0 & 4 & 3.8 & 4 & 3.5 & 4 & 3.9 & 4 & 3.7 \\
\hline 19 & This clinical placement is interesting & 4.4 & 5 & 4.2 & 4 & 4.1 & 4 & 4.3 & 5 & 4.2 \\
\hline 20 & I look forward to coming to this clinical placement & 4.2 & 4 & 4.2 & 4 & 4.0 & 4 & 4.2 & 4 & 4.1 \\
\hline 21 & No one is interested in my problems & 2.3 & 2 & 2.3 & 2 & 2.3 & 2 & 3.3 & 4 & 2.7 \\
\hline
\end{tabular}

ing preceptors participated in this study. All of them were full-time nurses employed at SEHA, holding a BSN degree, with 7.5 years as average years of experience in nursing, and 6.5 years in supervising nursing students. Their age ranged from 28 to 49 years, and they were from Indian, Filipino, and Arab ethnicities.

\section{Student Clinical Learning Culture}

To understand the learning culture on the DEU wards, nursing students had to answer 21 questions identified in the SCLC (Table 2). Each of the 4 groups representing a semester placement had scores averaged for each question with an overall weighted average score, described in this section as $M$, for the questions over the 2-year study period. Eighty-two total responses were received from 142 surveys distributed (57.7\%).

Analysis of students' surveys showed positive students' experiences and motivation with the DEU model. Students had a relatively positive experience with the unit's staff nurses. $64.2 \%$ of students (who answered "agree" and "strongly agree") reported that nurses explained the unit's work routine to them $(M=4.1), 71.4 \%$ reported 
Table 3. The Support Instrument for Nurses Facilitating the Learning of Others scores

\begin{tabular}{|c|c|c|c|c|c|c|c|c|c|c|}
\hline & & \multicolumn{2}{|c|}{$\begin{array}{l}\text { April } 2016 \text {, } \\
\text { Group } 1\end{array}$} & \multicolumn{2}{|c|}{$\begin{array}{l}\text { December 2016, } \\
\text { Group } 2\end{array}$} & \multicolumn{2}{|c|}{$\begin{array}{l}\text { April } 2017 \text {, } \\
\text { Group } 3\end{array}$} & \multicolumn{2}{|c|}{$\begin{array}{l}\text { December 2017, } \\
\text { Group } 4\end{array}$} & Total \\
\hline \multirow{5}{*}{$\begin{array}{l}1 \\
2\end{array}$} & \multirow{5}{*}{$\begin{array}{l}\text { Surveys } \\
\text { Surveys sent, } n \\
\text { Survey responses, } n\end{array}$} & \multirow{3}{*}{\multicolumn{2}{|c|}{$\begin{array}{l}38 \\
24\end{array}$}} & \multirow{3}{*}{\multicolumn{2}{|c|}{$\begin{array}{l}41 \\
28\end{array}$}} & \multirow{3}{*}{\multicolumn{2}{|c|}{$\begin{array}{l}44 \\
30\end{array}$}} & \multirow{3}{*}{\multicolumn{2}{|c|}{$\begin{array}{l}51 \\
23\end{array}$}} & \\
\hline & & & & & & & & & & 174 \\
\hline & & & & & & & & & & 105 \\
\hline & & \multicolumn{2}{|c|}{$\begin{array}{l}\text { April 2016, } \\
\text { Group } 1\end{array}$} & \multicolumn{2}{|c|}{$\begin{array}{l}\text { December 2016, } \\
\text { Group } 2\end{array}$} & \multicolumn{2}{|c|}{$\begin{array}{l}\text { April } 2017 \\
\text { Group } 3\end{array}$} & \multicolumn{2}{|c|}{$\begin{array}{l}\text { December 2017, } \\
\text { Group } 4\end{array}$} & \multirow{2}{*}{$\begin{array}{l}\text { Total } \\
\begin{array}{l}\text { weighted } \\
\text { average }\end{array}\end{array}$} \\
\hline & & mean & median & mean & median & mean & median & mean & median & \\
\hline 1 & $\begin{array}{l}\text { Questions } \\
\text { A member of the nursing team thanks me when I am } \\
\text { working with a learner }\end{array}$ & 3.4 & 4 & 3.9 & 4 & 3.8 & 4 & 4.0 & 4 & 3.8 \\
\hline 2 & I have sufficient time to answer a learner's questions & 3.4 & 4 & 3.6 & 4 & 3.3 & 4 & 3.8 & 4 & 3.5 \\
\hline 3 & I know how to find out the scope of practice of the learner & 3.9 & 4 & 3.9 & 4 & 3.9 & 4 & 3.8 & 4 & 3.9 \\
\hline 4 & I am able to facilitate the learning of others & 3.9 & 4 & 3.8 & 4 & 3.7 & 4 & 4.1 & 4 & 3.9 \\
\hline 5 & I have sufficient time to provide a learner with feedback & 3.5 & 4 & 3.5 & 4 & 3.3 & 3 & 3.8 & 4 & 3.5 \\
\hline 6 & I have sufficient time to facilitate a learner & 3.4 & 4 & 3.3 & 3.5 & 3.0 & 3 & 3.7 & 4 & 3.3 \\
\hline 7 & I know how to motivate a learner & 4.0 & 4 & 4.0 & 4 & 4.0 & 4 & 4.2 & 4 & 4.0 \\
\hline 8 & $\begin{array}{l}\text { I have sufficient time to supervise a learner when they } \\
\text { perform new skills }\end{array}$ & 3.5 & 4 & 3.3 & 4 & 3.2 & 4 & 3.8 & 4 & 3.4 \\
\hline 9 & $\begin{array}{l}\text { The team approach on my ward makes facilitating a learner } \\
\text { manageable }\end{array}$ & 3.8 & 4 & 4.0 & 4 & 4.0 & 4 & 3.9 & 4 & 3.9 \\
\hline 10 & $\begin{array}{l}\text { I am able to manage my usual workload when working } \\
\text { with a learner }\end{array}$ & 3.4 & 4 & 3.1 & 3.5 & 3.1 & 3.5 & 3.7 & 4 & 3.3 \\
\hline 11 & $\begin{array}{l}\text { I am assisted to implement strategies to improve a learner's } \\
\text { performance }\end{array}$ & 3.8 & 4 & 3.8 & 4 & 3.7 & 4 & 3.9 & 4 & 3.8 \\
\hline 12 & $\begin{array}{l}\text { I am assisted to develop strategies to improve a learner's } \\
\text { performance }\end{array}$ & 3.7 & 4 & 3.7 & 4 & 3.8 & 4 & 3.9 & 4 & 3.8 \\
\hline 13 & $\begin{array}{l}\text { I have the communication skills to constructively interact } \\
\text { with the learner }\end{array}$ & 4.0 & 4 & 4.1 & 4 & 4.1 & 4 & 4.2 & 4 & 4.1 \\
\hline 14 & $\begin{array}{l}\text { Members of the nursing team assist with my workload } \\
\text { when I am working with a learner }\end{array}$ & 3.6 & 4 & 3.7 & 4 & 3.6 & 4 & 3.6 & 4 & 3.6 \\
\hline 15 & $\begin{array}{l}\text { I know who to ask if I have questions about what a learner } \\
\text { can do }\end{array}$ & 4.1 & 4 & 4.1 & 4 & 3.9 & 4 & 4.1 & 4 & 4.1 \\
\hline 16 & $\begin{array}{l}\text { I know how to seek assistance if I am having difficulties } \\
\text { with a learner's attitude }\end{array}$ & 4.1 & 4 & 4.0 & 4 & 4.0 & 4 & 4.1 & 4 & 4.1 \\
\hline 17 & $\begin{array}{l}\text { The cooperation among the nursing team assists me } \\
\text { when I am working with a learner }\end{array}$ & 3.8 & 4 & 3.9 & 4 & 3.8 & 4 & 3.9 & 4 & 3.8 \\
\hline
\end{tabular}

that nurses helped them when they felt troubled with work ( $M=4.2), 70.3 \%$ reported that nurses talked with them as individuals $(M=4.0)$, and $64.2 \%$ reported that nurses considered their feelings $(M=3.9)$. In addition, $85.6 \%$ of students reported that the ward assignments were clear $(M=4.0)$, and $71.4 \%$ had good learning opportunities $(M=3.9)$. Besides, $82.1 \%$ of the students were looking forward to doing their placements $(M=4.1)$, and
$88 \%$ considered the placement as interesting $(M=4.2)$, indicating that the students are keen to learn during their clinical placement. Furthermore, students had relatively less weighted average scores when reporting that "clinical placement is boring" $(M=2.6)$, "clinical placement is a waste of time" $(M=2.7)$, and "the nurses are unfriendly and inconsiderate towards students" $(M=2.6)$. 


\section{Support Instrument for Nurses Facilitating the}

Learning of Others

The SINFLO tool was sent to 174 preceptors during nursing students' placements to understand nursing preceptors' perceptions of the support they received during students' placements. A total of 105 responses were received (60.3\%) (Table 3 ).

Analysis of the nursing preceptors' surveys generally revealed positive experiences. 98\% of the nursing preceptors (who answered "agree" and "strongly agree") reported that they had the communication skills needed to facilitate students' learning $(M=4.1), 86.8 \%$ knew whom to ask regarding students' learning $(M=4.1)$, and $91.2 \%$ knew how to seek assistance with difficult students $(M=$ 4.1). $73.8 \%$ of the preceptors reported positive cooperation among the nursing team, which assists in students' learning $(M=3.8)$, and $78.2 \%$ reported that they were assisted in developing and implementing strategies to improve learners' performance $(M=3.8)$. Additionally, $98 \%$ of the preceptors believed that they had good communication skills to interact constructively with the learners $(M=4.1)$. However, the preceptors had relatively lower scores with questions related to having enough time with the students. $73.8 \%$ reported that they did not have enough time to answer students' questions $(M=3.5), 78.2 \%$ did not have enough time to deliver feedback $(M=3.5), 69.5 \%$ to facilitate sufficient learning $(M=3.3)$, and $73.8 \%$ to supervise students' performance $(M=3.4)$.

\section{Focus Group Discussions}

Nine students were invited to participate in the focus group discussion in October 2018. Seven students agreed to participate $(77.78 \%)$. The rest of the students graduated in September and had commenced their graduate nurse intern program, and thus they were excluded so as not to influence the outcomes of the focus group. The questions asked during the focus group were based on the DEU model and the students' learning environment and their expectations. Students generally had positive perceptions of the DEU model. The majority of them were satisfied with the increased learning opportunities in a receptive learning environment, which helped achieve their learning needs and improve their self-esteem throughout the clinical placement. Also, students highlighted the significance of positive relationships with nursing preceptors for achieving their learning objectives while on clinical placements.

\section{Students' Understanding of the DEU Model}

Students were generally aware that the DEU is a collaboration model. They asserted that the DEU model provided them with better learning opportunities to improve their knowledge and skills under preceptor guidance. They stated, "DEU helps students achieve their goals and objectives," "teaches students to communicate with patients and the multidisciplinary team," and "improves students' better understanding of the nurse's role." Also, students expressed that the DEU "provides an environment to look after patients with confidence," "helps reducing possible harm and errors," and "ensures good patients' care and safety."

\section{Students' Learning Environment}

Students indicated that their training was dependent on their preceptor and their willingness to guide the student. They stated, "we kept following them (preceptors), and they blocked us." Most of the students agreed that most of the preceptors "would not ask the student to help them as they all felt it was too advanced for the students." Most of the students agreed that some of the preceptors received them positively, while some others were not as welcoming. They hoped that those who were not welcoming or interested in teaching the student would become "more friendly and supportive." They also hoped that preceptors would help them get "more opportunities to learn and allow them to have hands-on practice."

\section{Students' Expectations}

The students had positive perceptions of the DEU clinical model. They were also expecting authorities to "implement the model in more clinical areas to enrich students' clinical knowledge and experiences." Some students expressed that some nursing preceptors should "know their learning objectives" and "ask the students to read and review," "divide the job among the students," "teach everything and explain what they are doing," "create learning opportunities to practice," and "implement skills learned at college." Students also expressed that the preceptors should "liaise with other staff nurses when learning opportunities may be available," "assist students in identifying our weaknesses," "make students feel welcome to the unit," "supervise, guide and support," and be "friendly."

\section{Discussion}

Both quantitative and qualitative findings of the study showed generally positive perceptions of the DEU model in terms of its effect on facilitating better learning oppor-
Hooper/AlMekkawi/Williams/ Thompson/Zeeman 
tunities and learning environment for the nursing students. These findings were consistent with Nishioka et al.'s $[7,15]$ study that found positive learning experiences and influence on nursing students and their preceptors. Students indicated that the majority of nursing preceptors in the DEU model were able to provide excellent learning activities and communicate most of the time effectively. As a result, most of the students felt engaged, had a clear outline of their ward assignments, were keen to learn, and generally found the placement interesting. Providing students with enough learning opportunities would increase their participation in the culture of nursing and enhance their identity building [16]. Moreover, the DEU model provided an environment for nursing preceptors to feel more supported in their role and confident in being able to respond to the needs of the students, and, over time, there would be improvement in providing time and facilitating the learning needs of the students.

Implementing the DEU model facilitates creating new ways of teaching to enhance students' learning experiences, which can sometimes be challenging to nurse educators in this environment [1]. The findings of this study indicated that nursing preceptors have insight into the needs of the students, but they were challenged in finding enough time to provide for these needs consistently. The components of prioritization, learner motivation, allocating time for teaching, effective communication, providing and facilitating learning opportunities and feedback, and seeking support and utilization of resources within the team would all indicate that many of the preceptors are applying the knowledge and skills taught during preceptors' preparation workshops.

The study findings provided insight into students' experiences and highlighted that students are always in need of continuous guidance and support while on clinical placements. Besides, nursing preceptors have to receive better preparation to enrich students' overall experience and to ensure that both students and preceptors are getting the maximum benefit of the professional relationship. Careful selection of those chosen to be preceptors is critical. It is clear from the student responses that some preceptors had not embraced or applied the DEU principles as required. The selection of some preceptors may have been suboptimal at certain times on individual units. Therefore, setting specific selection criteria for nursing preceptors, which depend on their ability and interest to supervise nursing students, and seeking students' feedback while on clinical placements is necessary to identify early weaknesses and try to implement the needed changes more efficiently.
Nursing students exposed to the DEU model had the opportunity to develop their skills, better experience different events, reflect on their learning, and integrate and consolidate their academic knowledge in real clinical settings $[17,18]$. Students were also able to feel more accepted as part of the nursing team, which facilitates their active contribution to nursing care $[5,19]$. The responsibility they experience for their practice triggers further learning opportunities resulting in better relationships with the nursing staff members [20,21]. Besides, nursing staff working in the DEU model reported higher job satisfaction, opportunities for "teachable moments" [22], and valued students for their "fresh" eyes in the clinical setting $[23,24]$. Nursing staff members expressed positive feelings that they are investing in the future of the profession, and through this multitude of benefits, a greater sense of collaboration between clinicians, students, and academics emerges [21,23].

\section{Conclusion}

The study aimed to investigate participants' perceptions of the effectiveness of the DEU model in improving the learning experience of nursing students and their preceptors. Overall, the data collected from this study indicated that nursing students and preceptors had positive perceptions of the DEU model. Students reported that the DEU nurses explained the unit's work routine to them, helped them when they felt troubled, valued them as individuals, and considered their feelings while on clinical experiences. Besides, nursing preceptors reported positive cooperation among the nursing teams in the DEU model and receiving good support regarding students' learning. Nursing preceptors were able to receive good assistance to deal with challenging students and to develop and implement strategies to improve students' performance. The study has provided excellent insight into and information on the effectiveness of the DEU model in improving the learning experiences of nursing students. The DEU model can positively affect students' clinical experiences providing an environment for preceptors to deliver better teaching and enhance students' learning opportunities. The findings of this study also revealed some challenges to fulfil. There is a need to continue supporting nursing preceptors in order to have enough time with the students, deliver in-depth feedback, facilitate sufficient learning, and supervise students' performance. 


\section{Recommendations and Limitations}

The study proposed several recommendations to enhance students' learning and academic achievement during clinical placements. Firstly, providing a robust preceptorship and education program for the identified nursing preceptors in the units where the DEU model is adopted and implemented. Secondly, continue to support preceptors and students during clinical placements to ensure that the preceptor-student relationship is reaching its full potential and ensure careful selection of preceptors and student allocation. Thirdly, allocating a suitable patient load to nursing preceptors based on the students' level of clinical knowledge and skills. Fourthly, considering the adoption of the DEU model across other SEHA hospitals (partial or entirely) and modify future questionnaires to reflect a multicultural environment (comprehension of the English language for students who speak English as their second language). Fifthly, continue working with FCHS to increase the students' understanding of the DEU model before their clinical placements and re-evaluate the student to preceptor nurse ratio in light of this environment. Finally, there is also a need to ensure greater availability of the college facilitators in the hospital units, especially for students who do not receive adequate preceptor support.

Regarding the study limitations, the sample of nursing students was only from 1 regional educational institution. Therefore, the results may not be representative of all nursing institutions in the UAE. The more geographical diversity of educational sites may have permitted a more comprehensive view of the study phenomenon.

\section{Acknowledgment}

The authors wish to acknowledge Ms. Dawn Kuzemski, former Assistant Director of Nursing, Tawam Hospital; Ms. Suzanne Oakley, former Clinical Resource Nurse, Tawam Hospital; and Dr.
Corrien Van Belkum, former Head of Nursing Program, FCHS, for their contribution during phases of the study.

\section{Statement of Ethics}

The study received ethical approval from the Al Ain Hospital Research Ethics Governance Committee before the commencement of the data collection (referencenumber:AAHEC-06-18-096). The aim of the study was explained to all participants before data collection. Participants' anonymity and confidentiality were continuously guaranteed and protected throughout the study. The electronic data were securely stored in a password-protected laptop. The data were backed up with an external hard drive. The paper data were securely stored with the principal investigator in a locked filing cabinet. All data will be retained for 5 years by the fifth principle of the UK Data Protection Act (1998) as it applies to research. All paper data will be destroyed after 5 years using a paper shredder to maintain the subjects' confidentiality.

\section{Conflict of Interest Statement}

The authors declare no conflicts of interest; this article does not concern any commercial product.

\section{Funding Sources}

This study was not funded by any organization.

\section{Author Contributions}

R.A.H.: The principal investigator, data analyst, and completing the ethical approvals. M.A.: Data analyst, manuscript revision, proofreading, and corresponding author. G.W.: Data analyst, manuscript revision, proofreading, and completing the ethical approvals. B.T.: Data collector, data entry, data analyst, and manuscript revision. M.Z.: Data collector, data entry, data analyst, and manuscript revision.

\section{References}

1 Asadizaker M, Abedsaeedi Z, Abedi H, Saki A. Design and evaluation of reform plan for local academic nursing challenges using action research. Asian Nurs Res (Korean Soc Nurs Sci). 2016 Dec;10(4):263-70.

2 Aliafsari Mamaghani E, Rahmani A, Hassankhani H, Zamanzadeh V, Campbell S, Fast $\mathrm{O}$, et al. Experiences of Iranian nursing students regarding their clinical learning environment. Asian Nurs Res (Korean Soc Nurs Sci). 2018 Sep;12(3):216-22.
3 Tuohy C. Collaborative work with industry: implementation of dedicated education units [Internet]. Whitireia Nursing Journal. 2011; 18:25-38. Available from: https://search.informit.com.au/documentSummary; $\mathrm{dn}=3353$ 08559996319;res=IELNZC

4 Edgecombe K. Dedicated education units in nursing: The concept. In: Edgecombe K, Bowden $\mathrm{M}$, editors. Clinical Learning and Teaching Innovations in Nursing. The Netherlands: Springer; 2014. pp. 27-43.
5 Hannon PO, Hunt CA, Haleem D, King L, Day L, Casals P. Implementation of a dedicated education unit for Baccalaureate Students: process and evaluation. Int J Nurs Educ. 2012;4(2):155-9.

6 Polvado KJ, Sportsman S, Bradshaw P. Pilot study of a dedicated education unit: lessons learned. J Nurs Educ Pract. 2015;5(12):122.

7 Nishioka VM, Coe MT, Hanita M, Moscato SR. Dedicated education unit: student perspectives. Nurs Educ Perspect. 2014 Sep-Oct; 35(5):301-7. 
8 Benner P, Sutphen M, Leonard V, Day L. Educating nurses: A call for radical transformation. John Wiley \& Sons; 2009.

9 Creswel JW. Research design: Qualitative, quantitative, and mixed methods approaches. Los Angeles: University of Nebraska-Lincoln; 2009.

10 Henderson A, Briggs J, Schoonbeek S, Paterson K. A framework to develop a clinical learning culture in health facilities: ideas from the literature. Int Nurs Rev. 2011 Jun;58(2): 196-202.

11 Henderson A, Creedy DK, Cooke M, Walker R. Modification of a student feedback tool that provides feedback to staff in clinical contexts. J Clin Nurs. 2010 Oct;19(19-20):29368.

12 Fejzic J, Henderson A, Smith NA, Mey A. Community pharmacy experiential placement: comparison of preceptor and student perspectives in an Australian postgraduate pharmacy programme. Pharm Educ. 2013;13.
13 Henderson A, Eaton E, Burmeister L. Development and preliminary validation of a tool to measure nurses' support for facilitating the learning of others. Int J Nurs Stud. 2012 Aug. 49(8):1013-6.

14 Polit D, Beck C. Essentials of nursing research. Ethics. 2012;23(2):145-60.

15 Nishioka VM, Coe MT, Hanita M, Moscato SR. Dedicated education unit: nurse perspectives on their clinical teaching role. Nurs Educ Perspect. 2014 Sep-Oct;35(5):294-300.

16 Heidelburg T. Registered Nurses' Beliefs Regarding the Preparedness of Nursing Students Who Have Completed the DEU Program. Master's Thesis Nursing. Albany State University; 2017.

17 Gonda J, Wotton K, Edgecombe K, Mason P. Dedicated education units: 2 . An evaluation. Contemp Nurse. 1999 Dec;8(4):172-6.

18 Hunt DA, Milani MF, Wilson S. Dedicated education units: an innovative model for clinical education. Am Nurse Today. 2015;10(5): 46-9.

19 Moscato SR, Miller J, Logsdon K, Weinberg S, Chorpenning L. Dedicated Education Unit: an innovative clinical partner education model. Nurs Outlook. 2007 Jan-Feb;55(1):31-7.
20 Ranse K, Grealish L. Nursing students' perceptions of learning in the clinical setting of the Dedicated Education Unit. J Adv Nurs. 2007 Apr;58(2):171-9.

21 Wotton K, Gonda J. Clinician and student evaluation of a collaborative clinical teaching model. Nurse Educ Pract. 2004 Jun;4(2):1207.

22 Mulready-Shick J, Kafel KW, Banister G, Mylott L. Enhancing quality and safety competency development at the unit level: an initial evaluation of student learning and clinical teaching on dedicated education units. J Nurs Educ. 2009 Dec;48(12):716-9.

23 Grealish L, Bail K, Ranse K. 'Investing in the future': residential aged care staff experiences of working with nursing students in a 'community of practice'. J Clin Nurs. 2010 Aug; 19(15-16):2291-9.

24 Auxier N, Woodruff LL. Job Satisfaction and Intent to Leave Among Dedicated Education Unit and Traditional Clinical Teachers. J Contin Educ Nurs. 2018 Dec;49(12):575-80. 